\title{
Predicting Weight Composition of Fish Diet s: Converting Frequency of Occurrence of Prey to Relative Weight Composition
}

\author{
K.A. Stobberup ${ }^{*, 1}$, T. Morato ${ }^{2}$, P. Amorim ${ }^{2}$ and K. Erzini ${ }^{3}$ \\ ${ }^{1}$ Fragata Azul Lda., Lisbon, Portugal \\ ${ }^{2}$ DOP, Departamento de Oceanografia e Pescas, Universidade dos Açores, Horta, Portugal \\ ${ }^{3}$ CCMAR, Universidade do Algarve, Faro, Portugal
}

\begin{abstract}
Diet compositions expressed in weight are essential to determine the trophic relationships in energetic terms between the compartments within a system. Data from stomachs were compiled from a number of sources (62102 stomachs), covering four broad areas such as the Northwest Atlantic, South Africa, Senegal and the Azores Islands in order to explore the empirical relationships between the frequency of occurrence, which is of limited use in a modelling context, and the preferred index, relative weight composition. These empirical relationships were found to be highly significant.
\end{abstract}

Keywords: Fish diets, relative weight composition, frequency of occurrence.

\section{INTRODUCTION}

The growing interest in ecosystem-based management as a complementary approach to traditional single-species management has emphasized the importance of the availability of diet composition data. One such approach is the use of multispecies or ecosystem models for measuring fishery impacts on marine ecosystems, which is dependent on information on the trophic relationships between the components of the system (Hollowed et al. 2000) [1] (Mace 2001) [2] (Christensen and Pauly 2004) [3] (Christensen and Walters 2004) [4]. Another approach concerns the development of ecosystem indicators such as trophic level, derived from data on diet composition, which has been proposed as a useful indicator of fisheries impacts on ecosystems (Pauly et al. 1998) [5] (Pauly et al. 1998) [6] (Pauly et al. 2001) [7] (Pauly et al. 2002) [8] (Stergiou et al. 2007) [9].

Studies describing diet composition and feeding habits of fish through the examination of stomach contents are fairly standard and literature on this subject is abundant. There is, however, a general lack of consistency in presenting the results, which reduces the number of studies suitable for specific and comparative analyses (Cortés 1997) [10]. This study focuses on one such index, the frequency of occurrence of prey in the diet, defined as the percentage of fish stomachs analysed containing a particular prey item irrespective of the amount. It gives an indication of specific food habits but no information whatsoever on the contribution to the diet in energetic terms. Data on frequency of occurrence is generally considered to be of no use in modelling studies, where the definition of diet in weight or energetic content is essential. This is particularly unfortunate when the only

*Address correspondence to this author at the Fragata Azul Lda., Lisbon, Portugal; Tel: +351 211534 677; E-mail: kstobberup@hotmail.com available information in a data-limited situation is expressed as frequency of occurrence (e.g. Longhurst 1957) [11].

The objective of this study was therefore to explore a possible empirical relationship between frequency of occurrence and relative weight of prey in diet composition or feeding ecology studies in order to predict the contribution in relative weight, when the latter is not available. The model is based mainly on diet data from the North Atlantic, but may be applied in other areas as a first approximation when there is a lack of information on number, volume or weight of prey in the diet.

\section{MATERIALS AND METHODS}

Diet composition data from 62,102 stomachs were compiled from a number of sources, covering four more or less broad areas: the Northwest Atlantic, South Africa, Senegal and the Azores Archipelago (Table 1). Emphasis was placed on gathering studies that provided diet composition both in terms of relative weight composition and frequency of occurrence. The data sources were peer-reviewed papers, online datasets, grey literature, and dissertations. As definitions of diet indices can vary, it is appropriate to define the relevant indices used in this study:

- Relative weight composition (called r.weight in our model) is defined as the weight of a prey item divided by the total weight of prey items observed in a predator diet. Data presented as relative prey volume was assumed to be equivalent to relative prey weight (MacDonald and Green 1983) [30].

- Frequency of occurrence (called r.occur in our model) is defined as the number of stomachs containing a prey item divided by the total number of non-empty stomachs for a specific predator species, usually expressed as a percentage $(\%)$. Thus, the sum of prey occurrences is 
Table 1. Data Sources On Fish Diet Composition Used in the Present Study

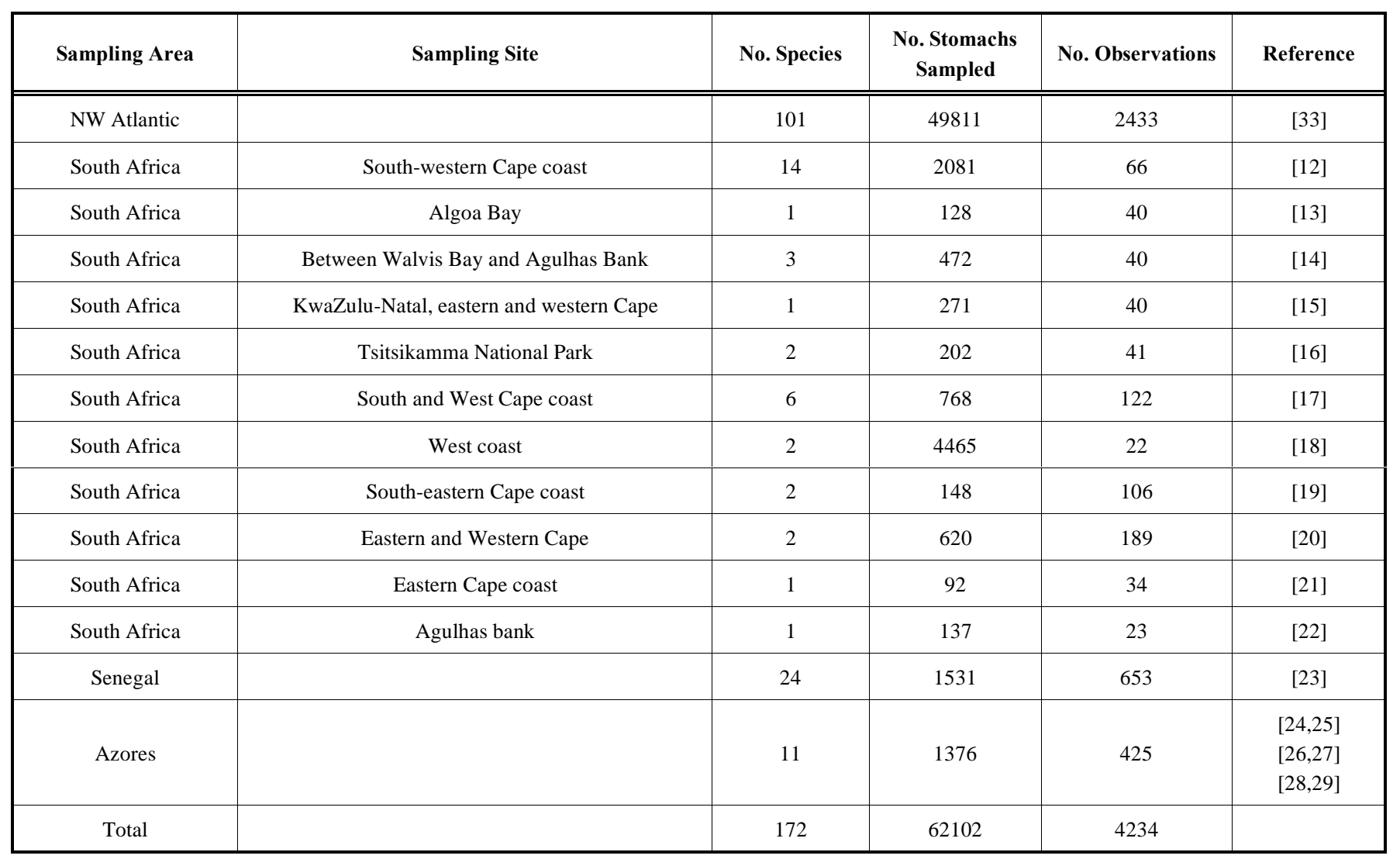

usually higher than $100 \%$ (or 1) for each predator species.

This definition of frequency of occurrence is the most common definition, but some studies include empty stomachs in the calculation. Also, we have encountered several studies, where the sum of occurrences adds up to $100 \%$, probably by re-scaling. These differences in definition are often not clearly stated and therefore a comparison of results from different studies should be handled with care.

\section{DATA SOURCES}

The main source of stomach data from the Northwest Atlantic was the Food Web Dynamics Program (FWDP) database, from the National Marine Fisheries Service (NMFS), Northeast Fisheries Science Centre (NEFSC), provided by Dr. Rodney Rountree (http://www.fishecology.org), available for the period from 1973 to 1990 . However, as stomach sampling protocol changed in 1981, the present study considers only the period from 1981 to 1990 . Data is given as frequency of occurrence based on total number of stomachs, including empty, and mean prey volume. Thus, frequency of occurrence was re-calculated based on non-empty stomachs only (Table 1).

Stomach data concerning South Africa were gathered from a number of publications on different species, which presented the results of stomach content analysis as frequency of occurrence and relative weight composition (Table 1). All of the Senegalese data originated from the work published by Andriamirado and Caverivière (1989) [23]. Data concerning the Azores were from peer-reviewed papers and a thesis (Morato 2001) [26].

\section{DATA PROCESSING AND ANALYSIS}

Stomach content data were grouped according to categories such as: sampling area, predator habitat, feeding type, predator size group, and prey group (Table 2). Sampling area refers to the four broad area described above. Predator habitat was adapted from FishBase 2000 (Froese and Pauly 2000) [31], but simplified to pelagic, benthopelagic and demersal categories. Most data sources indicated an average mean length or a range of lengths for each predator species, which were used to define three broad size classes (Small < $30 \mathrm{~cm} ; 30 \mathrm{~cm} \leq$ Medium < $60 \mathrm{~cm}$; and Large $\geq 60 \mathrm{~cm}$. If size data was not given, Fishbase 2000 was used to obtain an estimate of "Common length". Feeding types were defined on the basis of diet weight information, using the following criteria:

- Piscivore: fish constituted at least $75 \%$ of the diet.

- Benthivore: benthic prey constituted at least $75 \%$ of the diet.

- Herbivore: plants and macroalgae constituted at least 90 $\%$ of the diet.

- Omnivore: plants and macroalgae constituted at least 10 $\%$ of the diet.

- Planktivore: plankton constituted at least $75 \%$ of the diet. 
Table 2. Number of Observations According to the Defined Categories: Area, Habitat, Ps.Group (Predator Size Group), and Feeding Type

\begin{tabular}{|c|c|c|c|c|c|c|c|c|c|}
\hline Area Ha & bitat & Ps. Group & Feeding & & & & & & Grand Total \\
\hline \multirow[t]{4}{*}{ azores } & benthopelagic & large & & & & & 33 & & \\
\hline & & medium & & 87 & & & & & \\
\hline & & small & & & & & 54 & & \\
\hline & & small & & 58 & & & 54 & & \\
\hline azores Total & & & 85 & 145 & & & 195 & & 425 \\
\hline \multirow[t]{7}{*}{ nw.atlantic } & benthopelagic & large & & 191 & & & 1 & & \\
\hline & & medium & 18 & 178 & & & 2 & & \\
\hline & & medium & 211 & 510 & & & 249 & 8 & \\
\hline & & small & 109 & 351 & & & 58 & & \\
\hline & pelagic & large & & 15 & & & 25 & & \\
\hline & & medium & & 92 & & & 8 & & \\
\hline & & small & & 5 & & & & 48 & \\
\hline nw.atlantic Total & & & 461 & 1494 & & & 420 & 58 & 2433 \\
\hline \multirow[t]{3}{*}{ s.africa } & benthopelagic & large & & 20 & & & & & \\
\hline & & medium & & 25 & & & & & \\
\hline & & small & 16 & & 2 & 12 & & & \\
\hline s.africa Total & & & 327 & 150 & 4 & 17 & 158 & 67 & 723 \\
\hline \multirow[t]{8}{*}{ w.africa } & benthopelagic & large & 7 & 28 & & & 20 & & \\
\hline & & medium & 49 & & & & 8 & & \\
\hline & & small & 15 & & & & & & \\
\hline & demersal & large & 46 & 68 & & & 51 & & \\
\hline & & medium & 47 & 199 & & & 30 & & \\
\hline & & small & 8 & & & & 5 & & \\
\hline & pelagic & large & 15 & & & & 22 & & \\
\hline & & small & & 35 & & & & & \\
\hline w.africa Total & & & 187 & 330 & & & 136 & & 653 \\
\hline Grand Total & & & 1060 & 2119 & 4 & 17 & 909 & 125 & 4234 \\
\hline
\end{tabular}

- Carnivore: others, diet consisted primarily of fish and cephalopods.

The level of identification of prey items varied depending on the data source, but it was generally detailed. In order to make statistical analysis feasible and more generally applicable results, the prey were grouped into very broad categories:

- Benthic crustaceans: shrimps, crabs, lobsters, etc. 
- Benthic invertebrates: not included elsewhere, for example Anthozoa, Ascidiacea, Bryozoa, etc.

- Cephalopods: squid, cuttlefish and octopus, including pelagic and demersal species.

- Echinoderms: starfish and brittle stars as well as Holothuroidea

- Fish: all fish species

- Molluscs: bivalves and gastropods primarily.

- Zooplankton: copepods, euphausiids, mysids, etc., as well as fish and crustacean larvae and eggs

- Plants: macroalgae and various plants, which were often not specified

- Worms: polychaetes primarily.

Apart from the above-mentioned groups, a phytoplankton group and a miscellaneous group that consisted of unidentifiable prey or detritus material were also defined. Observations of parasite occurrences in the stomachs were classified as miscellaneous and this group was excluded from the statistical analysis. Only prey items that contributed with at least $0.001 \%$ in relative weight of the predators' diet were included in the analysis. The zero-values thus eliminated from the analysis corresponded to $3.3 \%$ of total number of observations (144 obs).

The data was log-transformed and modelled using Generalized Linear Models, which allows for the possibility to include factors (R software used) (Dalgaard 2002) [32]. The factors included correspond to the categories defined above: area, predator habitat, feeding type, predator size group, and prey group.

\section{RESULTS}

A simple regression of the r.weight $\sim$ r.occur relationship was highly significant explaining $68 \%$ of the variation in the data. On the other hand, the model that included all factors
Table 3. Results of Model Variance Reduction Expressed in Adjusted $\mathbf{R}^{2}$ (Adjusted on De grees on Free dom) for the $r$.weight $\sim \mathbf{r}$.occur $R$ elationship. $T$ he Model $C$ hosen for Subsequent Prediction is Highlighted and R efers to r.weight (log) as a Function of r.occur (log) Including the Effects of Prey Type on the Slope and Intercept of the Regression Line

\begin{tabular}{|c|c|c|c|c|}
\hline Factors Included & F Statistic & df & Adj. $^{2}$ & $\begin{array}{c}\mathbf{p} \\
\text { Value }\end{array}$ \\
\hline \hline $\begin{array}{c}\text { prey + feeding + habitat } \\
\text { + area + ps.group }\end{array}$ & 537.7 & 4211 & 0.736 & 0.000 \\
\hline $\begin{array}{c}\text { prey + feeding + habitat } \\
\text { + area }\end{array}$ & 581.0 & 4213 & 0.733 & 0.000 \\
\hline prey + feeding + habitat & 667.2 & 4216 & 0.728 & 0.000 \\
\hline prey + feeding & 755.0 & 4218 & 0.728 & 0.000 \\
\hline prey (+interaction) & $\mathbf{5 8 5 . 1}$ & $\mathbf{4 2 1 4}$ & $\mathbf{0 . 7 2 4}$ & $\mathbf{0 . 0 0 0}$ \\
\hline prey & 1095.0 & 4223 & 0.721 & 0.000 \\
\hline none & 8996.0 & 4232 & 0.680 & 0.000 \\
\hline
\end{tabular}

added only $6 \%$ to the variation explained (adjusted $\mathrm{R}^{2}=$ 0.736) (Table 3). The small increase in the variation explained showed that many of the included factors had limited explanatory power. The factor prey type was clearly important, resulting in a $4 \%$ increase in explanatory power, but all other factors could be eliminated without serious loss (loss of $1.5 \%$ in explanatory power). Including an interaction term (the effect on the slope of the regression line) did not result in a clear improvement, but was maintained in the model because of its highly significant effect (Table 4).

Not surprisingly, the effect of the various prey types was of particular importance in the model (Table 4; Fig. 1). This

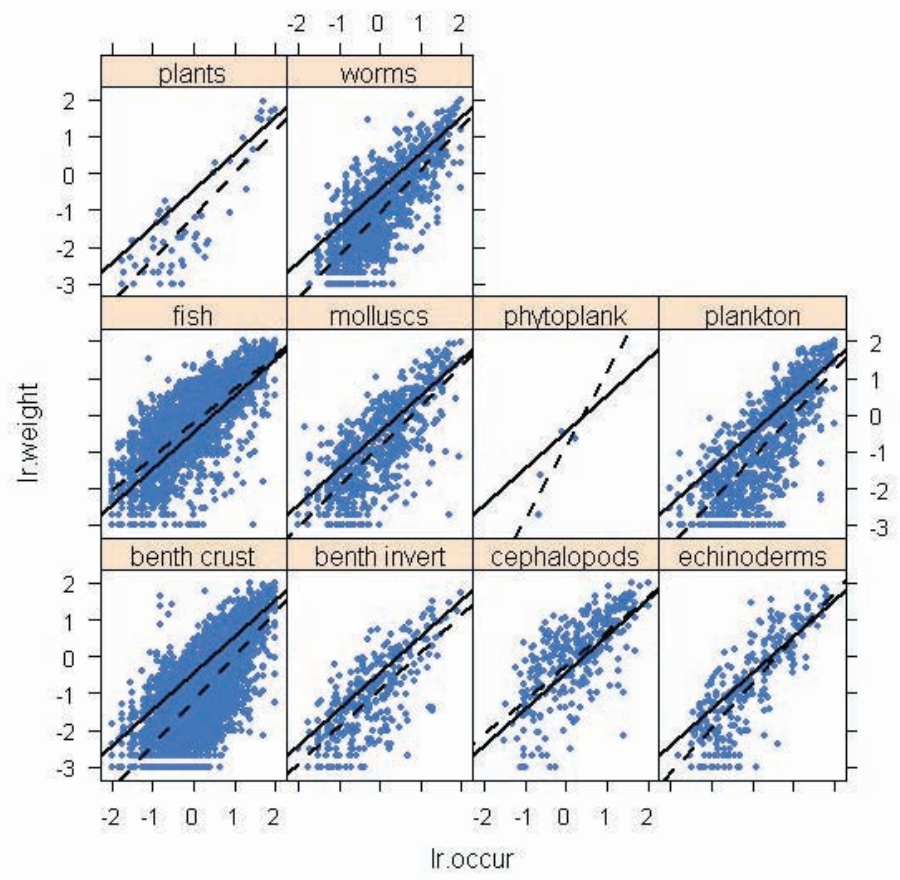

Fig. (1). Plot of r.weight as a function of r.occur considering the effects of prey categories. The reference line (bold) corresponds to a simple regression without the effects of prey, while the broken line is an independent regression of the observations (not to be confused with the equations given in Table 5). 
Table 4. Regression Coefficients for the r.weight r.occur Relationship, which is a Linear Model with the Following General form: $($ lr.weight $)=a($ intercept $)+b($ lr.occur $)+c_{i}($ prey $)+i_{i}($ lr.occur:prey); where Ir.weight is the Log-Transformed Relative Weight, Ir.occur is the log-Transformed Frequency of Occurrence, a the Intercept, $b$ the Slope, $c_{i}$ the Coefficients of the factor term Depending on prey type (Additive Term on the Intercept), and $i_{i}$ Refers to the In teraction Term Depending on Prey Type (Additive Term on the Slope). 95\% Confidence Band Calculated as: 2.064*std. Error / Estimate

\begin{tabular}{|c|c|c|c|c|c|}
\hline Coefficients & Estimate & Std. Error & Conf. Band & t Value & $\operatorname{Pr}(>|\mathbf{t}|)$ \\
\hline prey_benth invert & -0.106 & 0.054 & $105.2 \%$ & -1.961 & 0.050 \\
\hline prey_cephalopods & 0.376 & 0.047 & $25.7 \%$ & 8.031 & 0.000 \\
\hline prey_fish & 0.487 & 0.023 & $9.9 \%$ & 20.898 & 0.000 \\
\hline prey_molluscs & 0.038 & 0.037 & $200.5 \%$ & 1.029 & 0.303 \\
\hline prey_phytoplank & -0.058 & 0.378 & $1342.8 \%$ & -0.154 & 0.878 \\
\hline prey_plankton & -0.023 & 0.039 & $351.1 \%$ & -0.588 & 0.557 \\
\hline lr.occur:prey_benth invert & -0.037 & 0.057 & $317.0 \%$ & -0.651 & 0.515 \\
\hline lr.occur:prey_cephalopods & -0.079 & 0.054 & $141.5 \%$ & -1.459 & 0.145 \\
\hline lr.occur:prey_echinoderms & 0.153 & 0.060 & $80.8 \%$ & 2.554 & 0.011 \\
\hline lr.occur:prey_fish & -0.102 & 0.025 & $50.1 \%$ & -4.118 & 0.000 \\
\hline lr.occur:prey_molluscs & -0.014 & 0.039 & $572.5 \%$ & -0.361 & 0.719 \\
\hline lr.occur:prey_phytoplank & 0.209 & 0.959 & $946.8 \%$ & 0.218 & 0.827 \\
\hline lr.occur:prey_plankton & 0.089 & 0.039 & $91.6 \%$ & 2.253 & 0.024 \\
\hline
\end{tabular}

Residual standard error: 0.595 on 4214 degrees of freedom; Multiple R-Squared: 0.7251, Adjusted R-squared: 0.7239; F-statistic: 585.1 on 19 and 4214 DF, p-value: < 2.2e-16

was especially the case of fish as prey, where both of the additive terms on the intercept and slope were highly significantly ( $\mathrm{p}<0.001)$. A significant higher intercept was observed in the case of cephalopod and fish prey. For echinoderm and plankton prey the slope was significantly steeper.

Various conversion equations were defined on the basis of the regression model (Table 5). Note however that the effects are not significant for specific prey types such as benthic invertebrates, molluscs, phytoplankton, plants and worms. For example, what looks like a clearly significant effect in the case of phytoplankton (Fig. 1) is in fact not significant, probably due to the low number of observations (Table 4). In such cases it would be acceptable to use the base regression line, which corresponds to benthic crustaceans (Table 5; equation 1).

The distribution of model residual errors was slightly skewed, but the regression technique is considered to be a robust method, allowing slight deviations from the normal distribution (Appendix 1). A long list of possible interactions were tested and found not to be significant or of limited value, but the results are not shown in order to simplify the presentation of the results.

\section{DISCUSSION}

It is generally difficult to standardize over different studies, so the approach used in the present study was to adopt broad prey categories. A lot of information is lost in this process and prey categories may include organisms of very different characteristics, but the results can be made more generally applicable. Occurrences of prey items, contributing with less than $0.001 \%$ in weight (zero-values), were excluded from the analysis as well as prey identified as miscellaneous. The number of observations that were excluded corresponded to about $6 \%$ of the total (zero-values: $3 \%$ ).

There are many sources of variation when considering the diet composition of fish, which can stem from ecological factors or sampling procedures. Possible effects of sampling 
Table 5. Equations for Conve rting from Fr equency of $O$ ccurrence to $R$ elative Weight $E$ stimates, $T$ aking into A ccount $V$ arious $T$ ypes $o f P$ rey. $B$ ased $o n$th e $C$ oefficients of the GLM Model (Table 4)

\begin{tabular}{|c|c|c|}
\hline & Prey Type & Conversion Equation \\
\hline 1 & benthic crustaceans & $y=-0.654+1.051 x$ \\
\hline 2 & benthic invertebrates & $y=(-0.654-0.106)+(1.051-0.037) x$ \\
\hline 3 & cephalopods & $y=(-0.654+0.376)+(1.051-0.079) x$ \\
\hline 4 & echinoderms & $y=(-0.654+0.110)+(1.051+0.153) x$ \\
\hline 5 & fish & $y=(-0.654+0.487)+(1.051-0.102) x$ \\
\hline 6 & molluscs & $y=(-0.654+0.038)+(1.051-0.014) x$ \\
\hline 7 & phytoplankton & $y=(-0.654-0.058)+(1.051+0.209) x$ \\
\hline 8 & plankton & $y=(-0.654-0.023)+(1.051+0.089) x$ \\
\hline 9 & plants & $y=(-0.654-0.026)+(1.051+0.123) x$ \\
\hline 10 & worms & $y=(-0.654-0.055)+(1.051+0.049) x$ \\
\hline
\end{tabular}

were ignored as the source of information covered many studies, using various methodologies. On the other hand, the approach used to define categories is one way of attempting to identify possible effects of ecological factors such as area (i.e. ecosystem), predator habitat and size as well as feeding type. Surprisingly, all of these factors had limited explanatory power and could be ignored with minimal loss in variance reduction. Habitat was the only factor not found to be significant (at the $5 \%$ level), which was considered to be a result of the importance of prey, thus making the factor habitat redundant.

A simplified model was chosen for the r.weight $\sim$ r.occur relationship, including the effect of prey on both the intercept and slope. This model was highly significant ( $\mathrm{p}<0.001)$ and explained $72 \%$ of the variation in the data, which may be considered a surprising result when taking into account all the various sources of variation as explained above. Although this model could be improved by adding further factor terms, we consider the simplified model satisfactory for a combination of explanatory power and ease of application. The model states that, on average, more frequently occurring prey species constitute an increasing part of the diet in terms of relative weight. Note that we do not even attempt to estimate absolute weights on the basis of occurrence. Although the effect of area could be ignored for general purposes, this effect was highly significant $(p<0.001)$. This was observed as lower intercepts for Azores and Senegal, indicating generally lower relative weights compared to the Northwest Atlantic and South Africa. Considering the general variability of diet data, we would nevertheless recommend the use of the conversion equations to obtain a first preliminary estimate (Table 5), if the only available data is frequency of occurrence.

It should also be noted that the coefficients estimated by the model are relatively precise in case of prey such as benthic crustaceans (the base regression line), cephalopods, and fish (Table 4: conf. band). This is however not the case for phytoplankton. Some examples have been prepared to illustrate this varying precision by including $95 \%$ confidence bands (Appendix 2).
As far as we know, the present study is the first attempt to explore an empirical relationship between relative we ight composition and frequency of occurrence. Frequency of occurrence data has generally been considered to be of no use in quantifying trophic relationships as most recent modeling and indicator methods are built on biomass or energetic considerations. It was therefore surprising to observe in initial trials that this relationship could be modeled relatively well when considering relative and not absolute weights. This is of special relevance as many historical or earlier studies used the frequency of occurrence method to characterise fish diets and may be in some cases the only data available.

\section{ACKNOWLEDGEMENTS}

We would like to thank Ana Moreira (INIAP-IPIMAR) for assisting us in the processing of data and Dr. Rodney Rountree for his consent on the use of data from the FWDP programme. Furthermore, we thank Daniel Pauly and Deng Palomares for their encouraging words and the anonymous reviewers for improving this paper.

Appendix 1. Histogram and plot of model residuals, referring to the reduced model (Table 4)
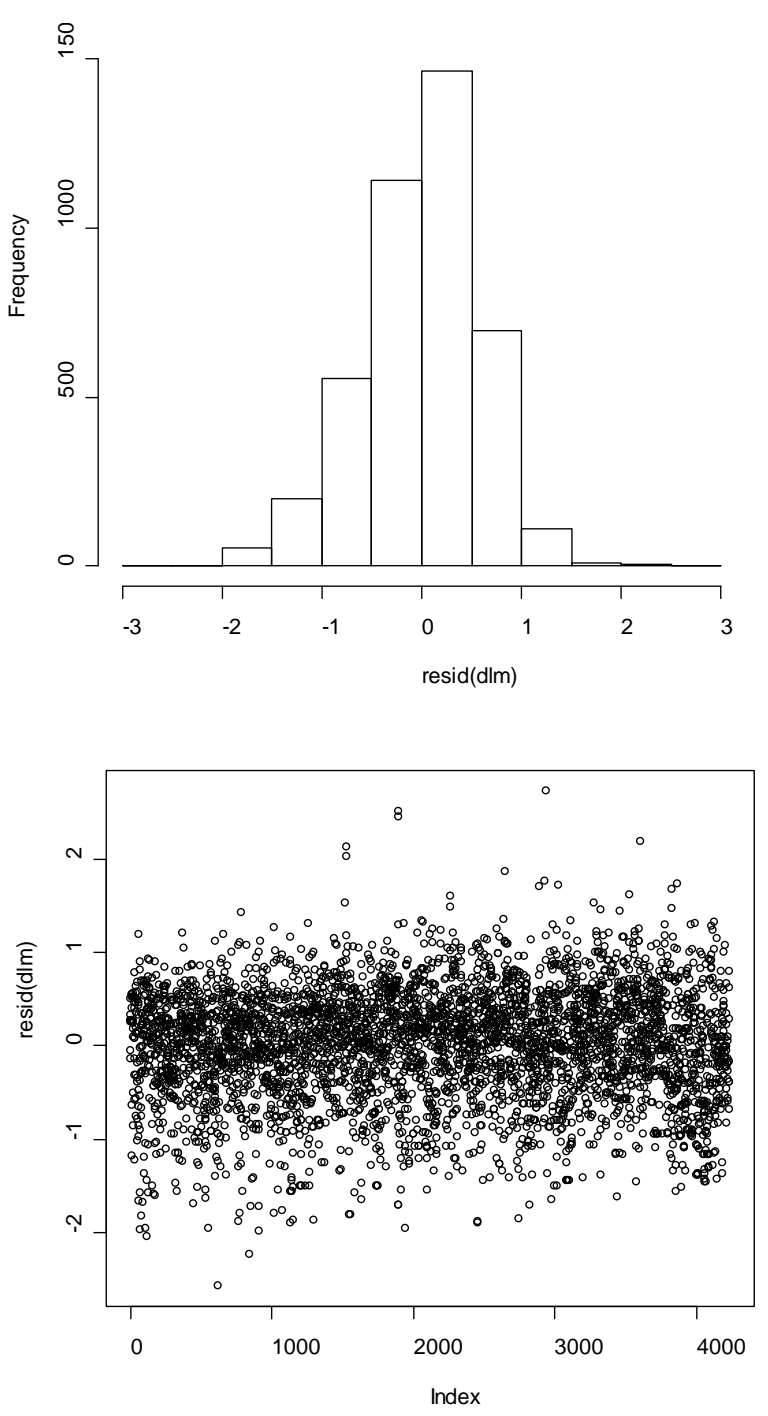
Appendix 2. Plots of Ir.weight Ir.occur Showing Model Estimates and 95\% Confidence Band for Three Examples: Fish (High Precision), Molluscs (Medium Precision) and Phytoplankton (Low Precision)
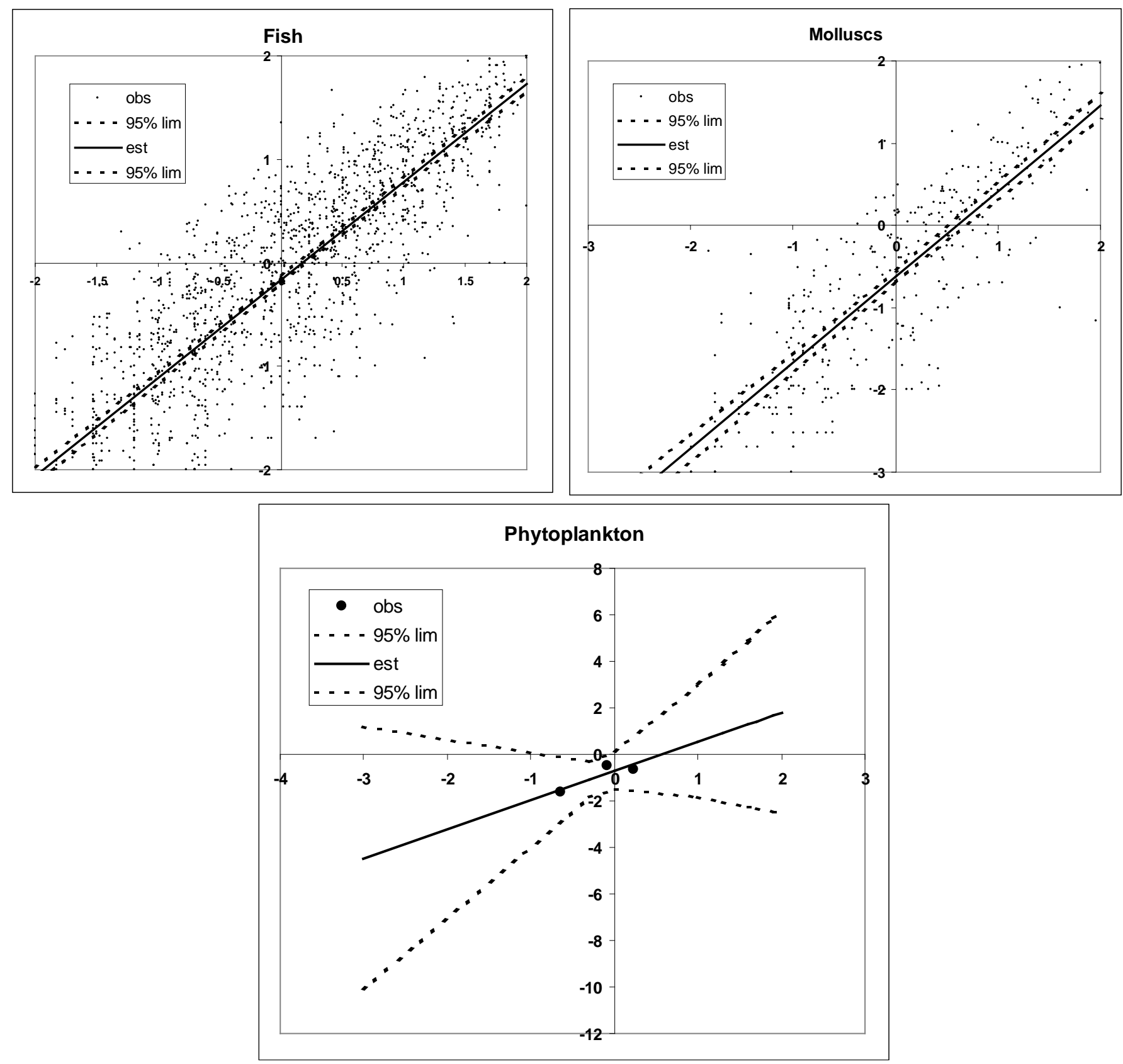

\section{REFERENCES}

[1]

Hollowed AB, Bax N, Beamish R, et al. Are multispecies models an improvement on single-species models for measuring fishing impacts on marine ecosystems? ICES J Mar Sci 2000; 57: 707-19. approaches to fisheries stock assessment and management. Fish Fish 2001; 2: 2-32.

[3] Christensen V, Pauly D. Placing fisheries in their ecosystem context, an introduction. Ecol Model 2004; 172: 103-7.

[4] Christensen V, Walters CJ. Ecopath with ecosim: methods, capabilities and limitations. Ecol Model 2004; 172: 109-39.

[5] Pauly D, Christensen V, Dalsgaard J, Froese R, Torres F, Jr. Fishing down marine food webs. Science 1998; 279(5352): 860-3.

[6] Pauly D, Trites AW, Capuli E, Christensen V. Diet composition and trophic levels of marine mammals. ICES J Mar Sci 1998; 53: 467-81.
[7] Pauly D, Palomares ML, Froese R, et al. Fishing down Canadian aquatic food webs. Can J Fish Aquat Sci 2001; 58(1): 51-62.

[8] Pauly D, Christensen V, Guénette S, et al. Towards sustainability in world fisheries. Nature 2002; 418: 689-95.

[9] Stergiou KI, Moutopoulos DK, Hernando Casal JA, Erzini K. Trophic signatures of small-scale fishing gears and their implications for conservation and management. Mar Ecol Prog Ser 2007; 333: 117-28.

[10] Cortés E. A critical review of methods of studyng fish feeding based on analysis of stomach contents: application to elasmobranch fishes. Can J Fish Aquat Sci 1997; 54: 726-38.

[11] Longhurst A. The food of the demersal fish of a West African estuary. J Anim Ecol 1957; 26: 369-87.

[12] Bennett BA. The diets of fish in three South-Western Cape estuarine systems. S Afr J Zool 1989; 24 (3): 163-77.

[13] Buxton CD. Feeding biology of the roman Chrysoblephus laticeps (Pisces: Sparidae). S Afr J Mar Sci 1984; 2: 33-42. 
[14] Ebert DA, Cowley PD, Compagno LJV. A preliminary investigation of the feeding ecology of catsharks (Scyliorhinidae) off the west coast of Southern Africa. S Afr J Mar Sci 1996; 17: 233-40.

[15] Griffiths MH. Feeding ecology of South African Argyrosomus japonicus (Pisces: Sciaenidae), with emphasis on the Eastern Cape surf zone. S Afr J Mar Sci 1997; 18: 249-64.

[16] Mann BQ, Buxton CD. Diets of Diplodus sargus capensis and D. cervinus hottentotus (Pisces: Sparidae) on the Tsitsikamma coast, South Africa. KOEDOE 1992; 35(2): 27-36.

[17] Meyer M, Smale MJ. Predation patterns of demersal teleosts from the Cape south and west coasts of South Africa. 1. Pelagic predators. S Afr J Mar Sci 1991; 10: 173-91.

[18] Pillar SC, Barange M. Diel variability in bottom trawl catches and feeding activity of the Cape hakes off the west coast of South Africa. ICES J Mar Sci 1997; 54 (3): 485-99.

[19] Smale MJ. The feeding biology of four predatory reef fishes off the south-eastern Cape coast, South Africa. S Afr J Zool 1986; 21(2): 111-30.

[20] Smale MJ, Compagno LJV. Life history and diet of two Southern African smoothhound sharks, Mustelus mustelus (Linnaeus, 1758) and Mustelus palumbes Smith, 1957 (Pisces: Triakidae). S Afr J Mar Sci 1997; 18: 229-48.

[21] Smale MJ, Goosen AJJ. Reproduction and feeding of spotted gully shark, Triakis megalopterus, off the Eastern Cape, South Africa. Fish Bull 1999; 97 (4): 987-98.

[22] Walmsley-Hart SA, Sauer WHH, Buxton CD. The biology of the skates Raja wallacei and R. pullopunctata (Batoidea : Rajidae) on the Agulhas Bank, South Africa. S Afr J Mar Sci 1999; 21: 165-79.

[23] Andriamirado GAR, Caverivière A. Les régimes alimentaires des prédateurs potentiels de la crevette Penaeus notialis au Senegal. Place trophique des crevettes. Centre de Recherches Océanographiques (CRODT), Dakar-Thiaroye (Sénégal), Document Scientifique 1989; 113: pp. 1-79.
[24] Morato T, Solà E, Grós MP, Menezes G. Diets of thornback ray (Raja clavata) and tope shark (Galeorhinus galeus) in the bottom longline fishery of the Azores, Northeastern Atlantic. Fish Bull 2003; 101: 509-602.

[25] Morato T, Solà E, Grós MP, Menezes G. Diets of forkbeard (Phycis phycis) and conger eel (Conger conger) off the Azores during spring of 1996 and 1997. Arquipélago Life Mar Sci 1999; 17A: 5164.

[26] Morato T, Santos RS, Andrade P. Feeding habits, seasonal and ontogenetic diet shift of blacktail comber, Serranus atricauda (Pisces: Serranidae), from the Azores, Northeastern Atlantic. Fish Res 2000; 49(1): 51-60.

[27] Morato T. Feeding ecology and trophic relationships of nine demersal fish species of the Azores. Masters' of Science Thesis. University of Coimbra, Faculty of Science and Technology: Coimbra, Portugal 2001; p. 119.

[28] Morato T, Solà E, Grós MP, Menezes G. Feeding habits of two congener species of seabreams, Pagellus bogaraveo and Pagellus acarne, off the Azores (northeastern Atlantic) during spring of 1996 and 1997. Bull Mar Sci 2001; 69(3): 1073-87.

[29] Figueiredo M, Morato T, Barreiros JP, Santos RS. Feeding ecology of the white seabream, Diplodus sargus, and the ballan wrasse, Labrus bergylta, in the Azores. Fish Res 2005; 75: 107-19.

[30] Macdonald JS, Green RH. Redundancy of variables used to describe importance of prey species in fish diets. Can J Fish Aquat Sci 1983; 40(5): 635-7.

[31] Froese R, Pauly D, Eds. FishBase 2000: concepts, design and data sources. ICLARM: Manila, Philippines 2000; p. 256.

[32] Dalgaard R. Introductory statistics with R. Springer-Verlag: New York 2002; p. 267.

[33] Food Web Dynamics Program (FWDP) database, from the National Marine Fisheries Service (NMFS), Northeast Fisheries Science Centre (NEFSC) (consulted on 1 Oct. 2006). Available from: http://www.fishecology.org/

Received: February 28, 2008

Revised: February 23, 2009

Accepted: February 24, 2009

(C) Stobberup et al.; Licensee Bentham Open.

This is an open access article licensed under the terms of the Creative Commons Attribution Non-Commercial License (http://creativecommons.org/licenses/by-nc/3.0/) which permits unrestricted, non-commercial use, distribution and reproduction in any medium, provided the work is properly cited. 